\title{
CORRESPONDENCE
}

We welcome letters to the Editor concerning articles which have recently been published. Such letters will be subject to the usual stages of selection and editing; where appropriate the authors of the original article will be offered the opportunity to reply.

Letters should normally be under 300 words in length, double-spaced throughout, signed by all authors and fully referenced. The edited version will be returned for approval before publication.

\section{FRACTURES OF THE CORACOID PROCESS}

Sir,

I read with interest the paper in the January 1997 issue by Ogawa et $\mathrm{al}^{1}$ entitled 'Fractures of the coracoid process'. The authors classify all fractures of the distal coracoid as type-II injuries but two varieties have been described: those between the coracoclavicular and coracoacromial ligaments and those at the tip. They advocate non-operative treatment for both, but the literature supports the use of surgical treatment in certain situations.

They also emphasise that fractures deep to the attachment of the coracoclavicular ligaments in association with other shoulder injuries may compromise the integrity of the linkage between the clavicle and the scapula. This may lead to considerable disturbance of function, and operation may be needed. The authors are describing a "double disruption" of the "superior shoulder suspensory complex".

\section{T. P. GOSS, MD}

University of Massachusetts Medical Centre

Worcester, USA.

1. Ogawa K, Yoshida A, Takahashi, M, Ui M. Fractures of the coracoid process. J Bone Joint Surg [Br] 1997;79-B:17-9.

2. Goss TP. Double disruptions of the superior shoulder suspensory complex. J Orthop Trauma 1993;7:99-106.

\section{Author's reply:}

Sir,

We thank Dr Goss for his pertinent comments. We realise that some authors have previously recommended surgical treatment for type-II fractures when the fragment is significantly displaced but we have not encountered this, probably because the fragment is usually attached to both the coracoacromial ligament and the

(C1997 British Editorial Society of Bone and Joint Surgery 0301-620X/97/47903 \$2.00

J Bone Joint Surg [Br] 1997;79-B:694-8. thick dorsal connective tissue. Even fractures of the tip are supported by connections between the coracoacromial ligament and the conjoint tendon formed by the ligamentous clavipectoral fascia. Thus, the indications for surgical treatment in acute cases are rare, particularly if the fracture is identified early and adequate conservative treatment given.

We fully agree with the second point made by Dr Goss.

K. OGAWA, MD

Keio University School of Medicine

Tokyo, Japan.

\section{UNIPOLAR OR BIPOLAR PROSTHESIS FOR DISPLACED INTRACAPSULAR HIP FRACTURE}

Sir,

We read with interest the study by Calder et al from Leicester in the May 1996 issue comparing unipolar with bipolar prostheses. ${ }^{1}$ We wish to make three comments.

First, randomised studies are welcome as the most valid means of providing answers to many important orthopaedic questions, but their interpretation demands critical attention. We wonder whether the apparently more rapid return to preinjury status in the Thompson group was more likely to be due to multiple significance testing than to a true difference. We can think of no mechanical or biological explanation for a true difference. A p value simply represents the probability that a finding may have occurred by chance. In the absence of a Bonferroni correction, the more outcome measures that are used, the more chance that one of them (erroneously) may have a 'significant' $\mathrm{p}$ value (a type I or alpha error). ${ }^{2}$

Secondly, since the only difference between the prostheses and their implantation was the design of the head, the most relevant outcome measure that could be objectively assessed is acetabular erosion. It is notable that three Thompson patients and no Monk patients had gross acetabular erosion on early radiographs. It would be interesting to learn, in a future study, whether the frequency of acetabular erosion becomes greater in the Thompson group with the passage of time and whether this radiological finding then has clinical significance.

We would also welcome the authors' opinion on the extent to which the results of this study may be extrapolated to younger patients or to the use of an alternative design of bipolar prosthesis.

D. WARWICK, MD, FRCS, FRCS Orth

I. D. LEARMONTH, FRCS, FRCS Ed, FCS(SA) Orth

S. WHITEHOUSE, BSc

Winford Unit

Avon Orthopaedic Centre

Bristol, UK.

1. Calder SJ, Anderson GH, Jagger C, Harper WM, Gregg PJ. Unipolar or bipolar prosthesis for displaced intracapsular hip fracture in octogenarians: a randomised, prospective study. J Bone Joint Surg [Br] 1996;78-B:391-4.

2. Altman DG. Practical statistics for medical research. London: Chapman and Hall, 1990:211,465.

THE JOURNAL OF BONE AND JOINT SURGERY 


\section{Author's reply:}

Sir,

We thank Mr Warwick and his colleagues for their interest in our paper. It is true that multiple significance testing increases the likelihood of finding a statistically significant difference in any one of the outcome measures, but it does not follow that a specific outcome measure is altered by the measurement of others, as they have implied. The outcome measures which we used were assessed prospectively and we felt that subjective return to preinjury status was probably the most important measure in this age group. We agree that a $p$ value should be taken with some measure of caution, especially as most clinical data are soft and a type-I error cannot be excluded. Although there is no obvious mechanical or biological explanation for the difference, it does not mean that one does not exist. The most important finding was expressed in the concluding paragraph:... "from our study there is no justification for the use of the ... bipolar hip prosthesis in patients over 80 years of age."

We agree that the difference in acetabular erosion rates is of interest and will be closely observed. A second study on younger patients (65 to 80 years) is under review, but the follow-up is currently insufficient. We would not extrapolate our findings in the older group to younger patients because we feel that the outcome requirements in the two groups, particularly early on, are different. It is not possible to comment on the bipolar design from this purely clinical study.

S. J. CALDER, FRCS Orth

Glenfield General Hospital

Leicester, UK.

\section{SIMPLE BONE CYSTS TREATED BY PERCUTANEOUS AUTOLOGOUS MARROW GRAFTING}

Sir,

We wish to comment on the article in the November 1996 issue by Lokiec et al ${ }^{1}$ entitled 'Simple bone cysts treated by percutaneous autologous marrow grafting'.

We have been using this technique since 1994 and have some concerns about their method. They used a needle to disrupt the lining membrane, making multiple perforations through the cyst wall into the medullary cavity. Trepanning of simple bone cysts is effective in decompressing the internal pressure of the cysts, improving the blood flow through the medullary bone of the cyst wall, stimulating the periosteum to induce bone formation, and eliminating bone destruction. ${ }^{2,3}$ It is, in itself, an effective method of treatment. The study does not distinguish between the effect of trepanning and of the additional grafting with bone marrow.

The authors claim that all intralesional septa were broken down by the needle. Have they undertaken a contrast examination to confirm this?

We have performed percutaneous autologous marrow grafting on seven patients with simple bone cysts avoiding multiple perforation. Although we routinely performed a further injection three weeks later our results were not as good. Complete healing eventually occurred in five patients but two had recurrence.

\section{E. GOKTURK, MD \\ N. KÖSE, MD \\ Osmangazi University Hospital \\ Eskiçsehir, Turkey.}

1. Lokiec F, Ezia D, Khermosh O, Wientroub S. Simple bone cysts treated by percutaneous autologous marrow grafting. J Bone Joint Surg [Br] 1996;78-B:934-7.
2. Komiya S, Minamitani K, Sasaguri Y, et al. Simple bone cyst: treatment by trepanation and studies on bone resorptive factors in cyst fluid with a theory of its pathogenesis. Clin Orthop 1993;287: 204-11.

3. Chigira M, Maehara S, Arita S, Udagawa E. The aetiology and treatment of simple bone cysts. J Bone Joint Surg [Br] 1983;65-B: 633-6.

4. Capanna R, Albisinni U, Caroli GC, Campanacci M. Contrast examination as a prognostic factor in the treatment of solitary bone cysts by cortisone injection. Skeletal Radiol 1984;12:97-102.

\section{Author's reply:}

Sir,

We thank Drs Göktürk and Köse for their interest in our paper.

We have previously used the technique of multiple perforation of the cysts and disruption of their lining membrane when injecting steroids. Our results were the same as those generally quoted in the literature, and we concluded that the mechanical disruption did not provide sufficient stimulus to heal a bone cyst.

In the new technique we perforate the cyst wall only once. From the same entry point, with the same needle, we ensure perforation of the distal wall to allow communication with the medullary cavity. We do not perform multiple perforations in the periphery of the cyst. We have used contrast media examination intraoperatively and have demonstrated that most of the septa were broken, forming a unicameral lesion.

We do not perform further injection on a routine basis. Most of the cyst is filled with bone marrow. We have treated 20 patients by this method and had to perform reinjection in only two for small residual lesions in the proximal femur six months after the first injection.

S. WIENTROUB, MD

Dana Children's Hospital

Tel Aviv, Israel.

\section{AN EVALUATION OF THE CONSTANT-MURLEY SHOULDER ASSESSMENT}

Sir

I read with interest the article in the March 1996 issue entitled 'An evaluation of the Constant-Murley shoulder assessment' by Conboy et al.

I think that Ms Conboy and her colleagues have missed the point of the system. The designers of the functional assessment score aimed to devise an easy-to-use reliable method using measurements of function which had a low intraobserver error and could be used for the study of progress after treatment. The original design was to assess function after injury. It worked well for this, and has been in widespread use for the past ten years gaining acceptance in Japan, Europe and the USA.

I am not certain what the detailed statistical analysis of 25 attempts at using the score was meant to achieve. It is recognised that there are some problems in the assessment of instability, particularly in high-level athletes, in which minimal scoring loss results in significant disability and the use of a quantification table associated with the Constant score is recommended. The specific scoring systems such as those of Rowe, Patel, and others can be utilised as required.

Presumably, the authors are now aware of the ongoing work with the Constant-Murley score which aims to improve its general acceptance. It is likely that a formal statement of the precise methodology will be forthcoming soon. 
C. R. CONSTANT, LLM, MCh, FRCS

Addenbrooke's Hospital

Cambridge, UK.

1. Conboy VB, Morris RW, Kiss J, Carr AJ. An evaluation of the Constant-Murley shoulder assessment. J Bone Joint Surg [Br] 1996; 78-B:229-32.

\section{Author's reply:}

Sir,

We have read Mr Constant's letter with interest. Any scoring system should be valid (assessing the issues which it is designed to assess), reliable and reproducible, sensitive to change, and practical and useful in the clinical setting.

We have found that the Constant-Murley shoulder assessment score has a low validity in cases of instability and that there is moderately high inter- and intraobserver variability in the painful shoulder due to arthritis or degenerative disease of the rotator cuff. It is essential that the amount of error is assessed carefully otherwise false conclusions may be drawn concerning the change in score due to treatment or time. This is why we undertook the study. We believe that the results are important and should be considered when using this method of scoring.

We use the Constant-Murley score and find it practical and helpful in assessing painful and degenerate conditions of the shoulder. Understanding of the errors that inevitably present with any assessment system will allow better appreciation of its value.

A. J. CARR, ChM, FRCS

Nuffield Orthopaedic Centre NHS Trust

Oxford, UK.

Sir,

We read with interest the article in the March 1996 issue entitled 'An evaluation of the Constant-Murley shoulder assessment' by Conboy et $\mathrm{al}^{1}$ and in particular the strength component of the score, which is important because it constitutes a quarter of the total available. A precise description of the authors' method for strength measurement is vital as we believe that the exact technique used and, in particular, the timing of the reading, may influence the absolute value obtained and the inter- and intraobserver error. In their original paper, Constant and Murley ${ }^{2}$ use and refer to the method of Moseley, which uses a spring balance unsecured at both ends. This method has never been described in detail either by Moseley or Constant and the lack of a standardised reproducible method has led to a search for others. ${ }^{4,5}$ The large strength constituent of the score also inevitably leads to a range of normal scores which is lower for women and falls with age, as clearly documented by Constant. ${ }^{6}$

Any method which is quick and convenient enough for use in clinical practice is bound to be arbitrary as it is difficult to control for even the most basic variables involved in strength measurement such as the length of the lever arm. Constant and Murley have never claimed that the score is useful for all shoulder conditions, merely that it can be applied to all shoulders. It is well known that the score is insensitive to conditions which may have only a minor or intermittent effect on shoulder function. Such patients should be evaluated by the diagnosis-specific scoring systems available, ${ }^{7-9}$ rather than a revised version of the Constant score. While a single scoring system for all shoulder conditions is an attractive proposition it is difficult to imagine a single rating scale which is suitable for the elderly patient with stiff painful arthritic shoulders and the high-performance throwing athlete who has discomfort only at the end of a game. Despite its disadvantages we believe that the Constant score remains extremely useful for the follow-up of individual patients with arthritis, cuff pathology, and fractures.

M. J. K. BANKES, BSc, FRCS

Royal National Orthopaedic Hospital Training Programme

Stanmore, UK.

R. J. H. EMERY, MS, FRCS Ed

St Mary's Hospital

London, UK.

1. Conboy VB, Morris RW, Kiss J, Carr AJ. An evaluation of the Constant-Murley shoulder assessment. J Bone Joint Surg $[\mathrm{Br}]$ 1996;78-B:229-32.

2. Constant CR, Murley AHG. A clinical method of functional assessment of the shoulder. Clin Orth 1987;214:160-4.

3. Moseley HF. Shoulder lesions. Edinburgh: E \& S Livingstone Ltd, 1969:28-9.

4. Gerber C. Integrated scoring systems for the functional assessment of the shoulder. In: Matsen FA, Fu FH, Hawkins RJ, eds. The shoulder: a balance of mobility and stability. Rosemont: American Academy of Orthopaedic Surgeons, 1993:531-50.

5. Bankes MJK, Emery RJH. Functional assessment, scoring and data collection for shoulder surgery. Ann Chirurg Gynaecol 1996: in press.

6. Constant CR. Age-related recovery of shoulder function after injury. MCh Thesis. University College, Cork, Ireland, 1986.

7. Rowe CR, Patel D, Southmayd WW. The Bankart procedure: a longterm end-result study. J Bone Joint Surg [Am] 1978;60-A:1-16.

8. Altchek DW, Warren RF, Wickiewicz TL, et al. Arthroscopic acromioplasty. J Bone Joint Surg [Am] 1990;72-A:1198-207.

9. Tibone JE, Bradley JP. Evaluation of treatment outcomes for the athlete's shoulder. In: Matsen FA, Fu FH, Hawkins RJ, eds. The shoulder: a balance of mobility and stability. Rosemont: American Academy of Orthopaedic Surgeons, 1993:519-29.

\section{Author's reply:}

Sir,

We thank Messrs Bankes and Emery for their comments on our paper.

We used a spring balance fixed to a solid block on the floor and by a strap to the wrist. The intervening strap was of variable length. It is also possible to use this method with the patient seated.

We agree that the large proportion of the score to which measurement of strength contributes can sometimes produce problems with reliability. This task is difficult to accomplish for reasons other than simple loss of strength in the shoulder, and accomplishment of the task appears to have poor reproducibility.

We agree that Constant and Murley have made a considerable contribution to the evaluation of shoulder conditions and that this score remains useful for the assessment of individuals with arthritis and degenerative conditions of the joint.

It is important that those using the score are aware that some intra- and interobserver error is likely to be present.

A. J. CARR, ChM, FRCS

Nuffield Orthopaedic Centre NHS Trust

Oxford, UK.

\section{CARE OF THE POLYTRAUMATISED PATIENT}

Sir,

I write concerning the Instructional Course Lecture by Drs Tscherne and Regel entitled 'Care of the polytraumatised patient' which was published in the September 1996 issue. They have 
produced a well-illustrated, comprehensive and practical article on the subject. I am concerned, however, about several of their specific recommendations.

First, they postulate that intramedullary reaming can exacerbate or worsen concomitant pulmonary dysfunction and they recommend stabilisation of femoral fractures by unreamed intramedullary nails. At present, there is little scientific evidence to support the move from reamed intramedullary nailing for femoral fractures to the less proven use of unreamed nailing. Preliminary data suggest that the incidence of pulmonary complications in polytraumatised patients whose femoral fractures are treated by plates or unreamed nails is no less than that in patients treated by reamed nails. There is also a trend towards more mechanical problems which is disturbing.

Secondly, the authors suggest that they use an intramedullary rod system for the treatment of forearm fractures to reduce the "known risks associated with the invasive approach required for plating." Most series of patients with forearm fractures treated by plating show rates of union of $95 \%$ to $98 \%$ with relatively few complications. Plating must be considered the treatment of choice for most forearm fractures, and intramedullary nailing, as they recommend, is an investigational approach at best.

Thirdly, immobilisation in a halo device has proved to be an effective method of treatment for 'hangman's' fractures, and leads to a high rate of union without the need for an anterior operation. While certain variants of this fracture may require operative stabilisation for persistent displacement, most patients with such injuries can be mobilised and treated successfully in a halo device. I disagree with the authors' recommendation for routine anterior fusion of $\mathrm{C} 2$ to $\mathrm{C} 3$ for the treatment of 'hangman's' fractures in patients with polytrauma.

These minor points do not, however, detract from the overall excellence of the article.

M. D. McKEE, MD, FRCS C

55 Queen Street East

Toronto, Canada.

1. Tscherne H, Regel G. Care of the polytraumatised patient. J Bone Joint Surg [Br] 1996;78-B:840-52.

\section{Authors' reply:}

Sir,

We thank Dr McKee for his comments on our article. The primary treatment of patients with multiple trauma must be distinguished from that of patients with an isolated injury. Some of the treatment regimes described in our article are not based on standardised concepts for monotrauma, but on the general condition of the patient. A flexible concept is needed.

Reamed nailing is a well-established method for the stabilisation of femoral fractures, with a relatively low complication rate in isolated trauma. Concomitant pulmonary problems, however, have been described in the last decade in association with multiple trauma and especially with significant pulmonary contusion. Deterioration of pulmonary function has been shown during reamed femoral nailing and has not been seen in an unreamed approach. Reaming seems to result in a significant rise of intramedullary pressure and embolisation of bone marrow into the lung which does not occur after unreamed nailing.

In our experience, fracture healing is even better with unreamed femoral nailing than with the reamed procedure. With unreamed nailing we are able to stabilise the femur using a minimally invasive approach. This reduces the destruction of intramedullary blood supply and the formation of necrotic bone in the intramedullary canal, thereby supporting fracture healing. Ipsilateral diaphyseal fractures of both the femur and tibia can be stabilised by one approach at the knee. The femoral nail is then applied retrograde. In a survey of German University Hospitals, we found that $72 \%$ of surgeons prefer the unreamed technique in isolated femoral fractures and only $22 \%$ the reamed technique. In patients with multiple trauma, and especially in those with associated thoracic trauma, $38 \%$ use the unreamed nail and the remainder external fixation. None performed reamed nailing.

Plating is still the 'gold standard' for the treatment of forearm fractures. In multiple trauma, however, we prefer intramedullary nailing since it is faster, less traumatising and causes less blood loss. We accept a higher rate of delayed bone healing and nonunion in this group.

Immobilisation in a halo device is an effective method of treatment used for 'hangman's fractures' and is also used routinely at our institution. In polytraumatised patients, however, this has several disadvantages. It interferes with adequate intensivecare treatment, it obstructs the positioning of the head and thorax and it interferes with excursion of the thorax, thereby contributing to the development of pulmonary problems. We therefore feel that anterior fusion is indicated in Effendi type-III fractures which need immobilisation after injury.

\section{H. TSCHERNE}

G. REGEL

Hannover Medical School

Hannover, Germany.

\section{REAMED OR UNREAMED NAILING FOR CLOSED TIBIAL FRACTURES}

Sir,

In their paper in the July 1996 issue entitled 'Reamed or unreamed nailing for closed tibial fractures', Court-Brown et al ${ }^{1}$ state that there is a significantly longer time to union after unreamed nailing and that it should not be used in the treatment of the common Tscherne $\mathrm{C} 1$ tibial fracture.

The authors are to be commended for instigating a prospective, randomised clinical trial on this much debated topic, but we think that their conclusion is flawed.

They state that the reason for the longer time to union in the unreamed groups is that five patients $(20 \%)$ required exchange nailing. Although they state that these exchange nailing procedures were necessary to facilitate union they present two radiographs which clearly show implant failure as the cause of the nonunion. Because patients were allowed to bear full weight as soon as they could, the high number of implant failures and malunions/nonunions could have been foreseen. Their protocol for the unreamed group contravened the recommendations of the manufacturers.

We reported a mean time to union of 14.9 weeks in 29 consecutive patients with closed tibial fractures treated by the AO unreamed nail, with no nonunions and no nail breakage. In this series weight-bearing was allowed only after six weeks.

P. HARRINGTON, FRCS I

Royal Infirmary

Hull, UK.

H. SMYTH, FRCS

G. C. FENELON, FRCS

I. SHARIF, FRCS

St James' Hospital

Dublin, Ireland.

1. Court-Brown CM, Will E, Christie J, McQueen MM. Reamed or unreamed nailing for closed tibial fractures. J Bone Joint Surg $[\mathrm{Br}]$ 1996;78-B:580-3.

2. Sharif I, Harrington P, Smyth $\mathbf{H}$, et al. Early experience using the AO unreamed tibial nail in two orthopaedic trauma units. J Bone Joint Surg [Br] 1994;76-B:Suppl I, 34. 


\section{Author's reply:}

Sir,

Mr Harrington and his colleagues are correct in that we did not follow the manufacturer's recommendations for weight-bearing after the use of the unreamed nail. We believe that it is unethical to deny weight-bearing to both groups of patients. Surgeons should not accept implants that demand non-weight-bearing to ensure their structural integrity.

They are wrong in their view that implant failure caused nonunion since it is the nonunion which causes the implant to fail.

I cannot comment on the trial conducted by Mr Harrington. It has been published only in abstract form and I am not clear as to the method used.

There is now ample evidence that reaming is osteogenic. Not only did Küntscher show this but it has also been demonstrated by a number of other workers over the last 50 years. I am aware of five prospective, randomised studies comparing reamed and unreamed femoral nailing all of which favour reamed nailing. $\mathrm{Mr}$ Harrington and his colleagues are the victims of a passing fashion which will decline in popularity.

C. M. COURT-BROWN, MD, FRCS Ed(Orth)

Royal Infirmary of Edinburgh

Edinburgh, UK.

\section{DEGENERATIVE CHANGES AT THE KNEE AND ANKLE RELATED TO MALUNION OF TIBIAL FRACTURES}

Sir,

We read with interest the paper in the September 1996 issue by van der Schoot et al ${ }^{1}$ entitled 'Degenerative changes at the knee and ankle related to malunion of tibial fractures'. We do not feel, however, that their data support the conclusion that malunion of fractures of the shaft of the tibia is associated with osteoarthritis of the knee and ankle.

Most of the paper relates to the radiological features of osteoarthritis rather than a detailed assessment of symptoms or function. The radiological changes were classified as grade $\mathrm{I}$ in $16 / 20$ knees and 22/37 ankles, but we do not consider that these criteria alone are sufficient to diagnose osteoarthritis, and note that Table IV suggests that most of the patients with grade-I changes had no joint symptoms. The small numbers of patients with grade-II and grade-III arthritis necessitated grouping of the data for analysis. It might have been better to have combined grade 0 and grade I (no arthritis or dubious arthritis) and grade II and grade III (definite arthritis).

Further analysis of the data using this grouping shows that there is a significant association between previous fracture of the shaft of the tibia and radiological evidence of osteoarthritis of the ankle ( $p<0.01$; McNemer test), but not for the knee $(p=0.125$; Binomial test). Table IV suggests that ankle symptoms did not correlate with radiological changes. Hence there is no definite evidence of an association between fracture of the tibial shaft and subsequent symptoms in either the knee or the ankle; all patients were able to resume normal work.

It is suggested that malunion could cause premature wear of joint cartilage by altering the transmission of forces, but three small studies have failed to show an association between malunion and osteoarthritis of the knee and ankle. ${ }^{2-4}$ Puno et al ${ }^{5}$ have shown that malorientation of the knee and ankle secondary to malunion is dependent on how distally the fracture is located. Van der Schoot et al did not look separately at the incidences of knee and ankle arthritis in their consideration of size and location of malunion. Merging the data in this way is unjustified, because it then fails to show whether or not arthritis of the knee is associated with proximal fractures and that of the ankle with distal fractures.

It is important to consider other possible reasons for an association between tibial fracture and subsequent arthritis, such as the effect of plaster immobilisation on articular cartilage, ${ }^{6}$ a minor concomitant articular cartilage injury or other undefined factors associated with the fracture.

We do not therefore consider that this paper shows convincing evidence of a causal association between malunion of fractures of the shaft of the tibia and osteoarthritis of the nearby joints.

S. MILNER, FRCS

D. GREENWOOD, MSc

Derbyshire Royal Infirmary

Derby, UK.

1. van der Schoot DKE, Den Outer AJ, Bode PJ, Obermann WR, van Vugt AB. Degenerative changes at the knee and ankle related to malunion of tibial fractures: 15 -year follow-up of 88 patients. $J$ Bone Joint Surg [Br] 1996;78-B:722-5.

2. Kristensen KD, Kiaer T, Blicher J. No arthrosis of the ankle 20 years after malaligned tibial-shaft fracture. Acta Orthop Scand 1989;60: 208-9.

3. Merchant TC, Dietz FR. Long-term follow-up after fractures of the tibial and fibular shafts. J Bone Joint Surg [Am] 1989;71-A:599606.

4. Puno RM, Vaughan JJ, Stetten ML, Johnson JR. Long-term effects of tibial angular malunion on the knee and ankle joints. J Orthop Trauma 1991;5:247-54.

5. Puno RM, Vaughan JJ, Von Fraunhofer JA, et al. A method of determining the angular malalignments of the knee and ankle joints resulting from a tibial malunion. Clin Orthop 1987;223:213-9.

6. Enneking WF, Horowitz M. The intra-articular effects of immobilisation on the human knee. J Bone Joint Surg [Am] 1972;54-A:97385 .

\section{Author's reply:}

Sir,

We thank Messrs Milner and Greenwood for their interest in our paper. It was not solely related to the radiological features of osteoarthritis. All patients were interviewed and examined clinically in detail after an average follow-up of 15 years. Patients with grade-I osteoarthritis showed radiological evidence of slight narrowing of the joint space, and/or small osteophytes and/or irregularity of the subchondral bone. Four of the six patients with joint symptoms had grade-I changes and hence such appearances could not be dismissed as dubious.

We could not demonstrate a statistical relationship between fractures in the distal part of the tibia and arthritis of the ankle or between fractures of the proximal part and problems at the knee. Eight of the 16 patients (50\%) with fractures of the distal part of the tibia had arthritis of the ankle as had 24 of the 62 patients (39\%) with fractures of the proximal and middle part of the tibia. Only one of the eight patients $(13 \%)$ with fractures of the proximal part of the tibia had arthritis of the knee. A further ten fractures were spiral or segmental and could not be properly classified.

Our study showed that there was a strong statistical association between fractures of the tibia and osteoarthritis of the adjacent joints and that tibial malalignment was a positive factor.

\section{A. J. DEN OUTER, MD \\ University Hospital \\ Leiden, The Netherlands.}

